\title{
Design of Teaching Methods Using Virtual Educational Environment
}

\author{
Boris Starichenko, Elena Antipova, Alexander Slepukhin, and Irina Semenova \\ Ural State Pedagogical University
}

\begin{abstract}
The purpose of the presented article is the review of approaches to design of modern methods of training developed and creation of design technology option of training methods in the conditions of using the virtual educational environment for formation of common cultural and professional competences of students of majoring in pedagogical education. Within the prescriptive theory by means of a subject and design method, conceptual modeling of a set of methods of students' training in the conditions of using information-communication saturated environment was carried out. The modeling allowed one to allocate design stages of methods of students' training in a pedagogical field of a "modern" educational paradigm when using the virtual educational environment. The general approach to design of activity of teachers including design of training methods on the basis of the accounting of main structural components of educational technologies is reflected in presented results. The given results of research of features and opportunities of the virtual educational environment allow one to define essence of enrichment of training methods and mechanisms of selfadjustment and self-improvement of the system of training methods in information educational environments, and to formulate a conclusion about impossibility of creation of the modern educational process without the virtual educational environment.
\end{abstract}

\section{Introduction}

Within formation and development of structural components of common cultural and professional competences of students of the pedagogical higher education institutions provided by federal state standard of higher education there is actual a question of formation technological literacy of future teachers.In addition, according to recommendations of UNESCO, it is relevant to develop students' ability to help pupils in using the information and communication technologies (ICT) for the organization of their successful cooperation, the solution of educational tasks, development of skills of the doctrine [1] in the conditions of ICT-saturated educational environment of a modern school. In the specified conditions of pedagogic and methodicalstudies conducted (for example, [2-9] and others), they are connected with studying features, opportunities and conditions of using the information educational environment of educational institution, personal educational environments, the virtual educational environment. The need to use information educational environments receives theoretical justification in educational process of many higher education institutions, in practical use of learning management systems, cloudy services and other information educational environments for the solution of educational and organizational tasks extends. Studies of questions of creating a technique of using information educational environments, training techniques with personal educational environments ([10], [11]), essence and features of a modern (information and communication) method of training [10], classification and design of methods of training in the conditions of using the educational environment were conducted as a result [10].

As this direction of pedagogical research is new in a depression phase (T. Kun terminology, 1964), a "modern" educational paradigm, predictingthe lack of a uniform approach to creation of the system of methods of training in information environments, distinction in understanding of a ratio of methods and forms of educational activity, essence of a training technique in conditions of using virtual educational environments, is observed. The option of activity of the teacher of design of methods of training when using virtual educational environments is offered within a contradiction between the need for creation of a training technique of students in conditions of using virtual educational environments for formation of common cultural and professional competences and ambiguity of understanding the structure of this technique (including features of the system of methods of training). Besides,there is also absence of the technology of designing the training methods of a "modern" educational paradigm in the considered materials.

\section{Methodology, research design \\ objectives}

and

\footnotetext{
*Corresponding author: antipova@uspu.me
} 
The purpose of the presented article is the review of approaches to design of modern methods of training developed and creation of the option of technology of design of methods of training in the conditions of using the virtual educational environment for formation of common cultural and professional competences in students majoring in pedagogical education.

Opening research methodology, we will indicate the need disclosures of essence and opportunities of use in educational process of the virtual educational environment, specification of a conceptual framework and allocation of features of methods of training of students in the virtual educational environment, the analysis of the existing technologies of design of methods of training of students.

So, for justification of the offered technology of design of methods of training, we will begin with consideration of essence and opportunities of use an educational process of the virtual educational environment.

Under the virtual educational environment (VEE), according to modern researches (in particular), we will understand network communication space in which the organization of educational process, its methodical and information support, documenting, interaction between all subjects of educational process, and also management to themare provided.

Despite the lack of the uniform approach to allocation of VEE structure, it is expedient to point to the interrelation of its following components specified by many authors: personal educational environments of the students (projected independently), personal environments of training of teachers, global and local networks, a learning management system - LMS, cloudy services. Use of opportunities of all set of the allocated components from the point of view of researchers promotes formation (development) of independence and activity trained, to increase of sensibleness of process of knowledge, formation of professional and common cultural competence.

In one of classifications of virtual educational environments (which basis its accessory is) there is the personal teaching environment (PTE) and the personal learning environment (PLE).

Commenting on features of each, the allocated environments, we will specify that, being guided by modern hardware decisions, within creation of PLE, it is supposed to create the Internet virtual space for an exchange and storage of educational information, ensuring communication, planning of activity, collecting and storage of results of training. For organization of such space, it is expedient (according to Starichenko B. [11]) to use the cloudy technologies realized on the Internet, and also means of the Web 2.0 services. Thus environment is built and developed by the trainee, including in it all components which are required for him for development of educational programs - substantial, tool, communication and other. Significant argument in favor of such environment is possibility of its development and use after graduation from the educational institution that provides practical support of the concept of the distributed continuous training during all life [12].

The personal teacher environment is formed by the teacher by a choice of network services and tools necessary for it and creation of the blog of discipline, in which work all allowed persons can take part. Certainly, the teacher has opportunity to place among all necessary training materials or links to them and necessary cloudy tools. Thus in PTE, the idea of creation of thematic network community that possesses motivational appeal to students is realized.

The virtual educational environment made of two specified environments in organizational and communicative aspect (according to [9]) represents difficult self-adjusted (due to expeditious correction of actions of participants of process of communication in relation to the changing situation) and self-improving (due to establishment of effective interrelation and its improvement in the process of assimilation of more difficult types of interrelations), the communicative system providing communication between participants of educational process. It is expedient to consider the allocated possibilities of the virtual educational environment when designing a technique of training in the ICT-saturated environment and creating a system of methods of training in the conditions of using VEE which, from our point of view, is enriched and updated in each phase of development of a "modern" paradigm.

We will specify a conceptual framework and we will mark out features of methods of training in the virtual educational environment.

Expansion of information educational space leads to emergence not only new means of ICT, but also to updating of all didactic system of training including, first of all, the new methods of training allowing to solve new didactic problems or tasks which earlier (without use of means of virtual environments) it would be impossible to solve completely theoretically or practically. With the advent of new methods of training (in particular, the research Semenova I. [13]), it is expedient to speak and about new methods of use of the virtual educational environment in educational process. We will specify a difference between the concepts "training methods with use of VEE" and "methods of use of VEE in training" in the allocated context.

The training method with use of the virtual educational environment is a set of joint actions of the teacher and trainees on the organization of an exchange of educational information and management of her perception, understanding, storing and the correct application by means of the information and communication means which are (and included trained) a part of VEE.

The method of using the virtual educational environment in training isa set of actions of the teacher (a choice of forms and ways of transfer of educational information, modeling of educational process, etc.) with use of information and communication means for achievement of the didactic purposes according to the diagnosed psychology and pedagogical situations. At allocation of the provided formulation we differentiate the concepts "method of use of VEE by the teacher in 
training" and "method of use of VEE trained in the exercise". So method of use of VEE trained in the exercise is an activity trained, based on means of the virtual educational environment, and undertaken by it for the solution of informative and (or) educational tasks.

In addition to the formulated definitions we will offer the following interpretation of the term a method of training by use of VEE: actions of the teacher and trained on broadcasting, processing and assimilation of a training material about VEE and its potential for the solution of educational and informative tasks. In this way VEE acts as a training subject which educational purpose isn't reduced only to development of a technological component, and includes also formation of skills of research of the communicative and developing VEE opportunities.

The accounting of the told allows to speak about selfadjustment and self-improvement of methods of training of students not only at the expense of a various range of the used tutorials which are (and included by the student) a part of VEE, but also at the expense of the allocated didactic opportunities of VEE.

We will carry out the short analysis of the existing technologies of design of methods of training of students.

For disclosure of essence of design of methods of training in traditional educational model we will address, for example, to M.E. Bershadsky and V.V. Guzeev's research where, in particular, the didactic bases of development of educational technology are presented and traditional methods of training are allocated: model, explanatory and illustrative, heuristic, programmed, problem (Bershadsky M. and Guzeev V. [2]).

The choice of a concrete method of training, from the point of view of the allocated authors, depends on answers to the following questions:

- whether it is necessary to actualize entry conditions at the beginning of educational occupation?

- whether it is necessary to formulate intermediate tasks during work on material of educational occupation?

- whether to offer ready ways of the solution of intermediate tasks or to provide to carry out a choice of a way trained independently?

- whether to show trained ready algorithms of the solution of total tasks or to allow them to make an independent choice of a way of the decision?

Answers to these questions also reflect logic of design of methods of training in "scientific" (the term Semenova I. [13]) an education paradigm.

In training model with use of ICT the choice of a method of training can be carried out with a support on new approaches to classification of modern methods of training. For example, possible design stages (choice) of a method of training with use of ICT within ideology of computer didactics can look as follows:

1) formulation of the didactic purpose (choice of target category);

2) selection and correlation of the making actions with features of informative processes as activity (so, for example, educational and informative tasks for application of cognitive processes of visual perception, spatial imagination, and also cogitative operations of the analysis, synthesis and classification etc. are necessary for formation of subject knowledge);

3) analysis of psychology and pedagogical conditions (duration of a course of studying of discipline; the level of the academic progress; the level of formation of psychophysiological qualities, personal characteristics of trainees; the level of technical equipment of audience etc.);

4) allocation of the realized pedagogical influences (a statement of material in a finished form; a material statement from other positions; reduction of examples of practical situations; organization of repeated control; reduction of the additional argument; discussion with audience of the different points of view, etc.);

5) creation of methods of training with use of ICT (methods of formation of communicative abilities; methods of individual-based training and control); a choice of methods of use of ICT for the representation (presentation) of training material, monitoring the procedure and diagnostics, correction of development which are trained, management of educational cognitive activity, individualization of educational cognitive activity;

6) diagnostics of results of training and the required correction of methods of training, including methods of use of ICT including supervision over reaction of the planned didactic purposes which are trained for their application, establishment of degree of success of achievement in advance allocated parameters etc.

Taking into account the allocated stages, we ([14-15]) presented the option of designing the methods of training in the mixed training model including methods of classroom, asynchronous, synchronous distance learning and in design and a combination of forms and methods of finding new knowledge, abilities, possession the traineesare engaged.

\section{Results and discussion}

As it was stated above, use of the virtual educational environment in educational process has the substantial, methodical and technological features which need to be considered at design of methods of training and methods of its use. We will present the option of design of methods of training developed in specialization of the results received by us in the conditions of allocation of feature of the virtual educational environment with a support on the main design stages of educational technology including:

- diagnostics and self-diagnostics of the level of the academic progress of the trainee, their psychophysiological features, educational requirements and professional interests, and also creation and accumulation of the information base containing the diagnostic data allowing to judge dynamics of development of competences and competencies of students; 


\section{Design of educational activity in conditions of using the virtual educational environment}

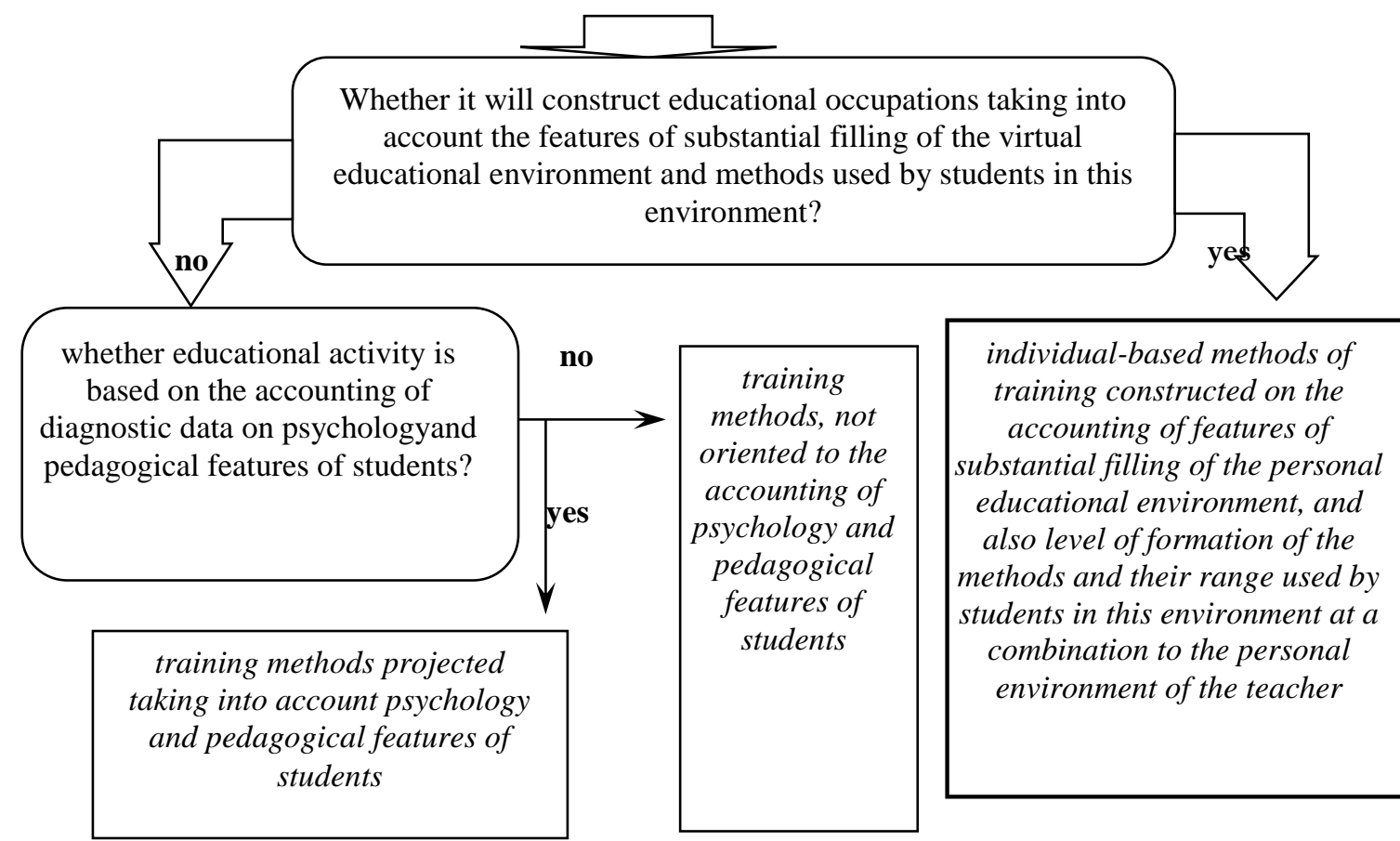

whether discussion with students of didactic tasks of educational occupation with a specification of target categories is organized (knowledge, abilities, possession, etc.)?
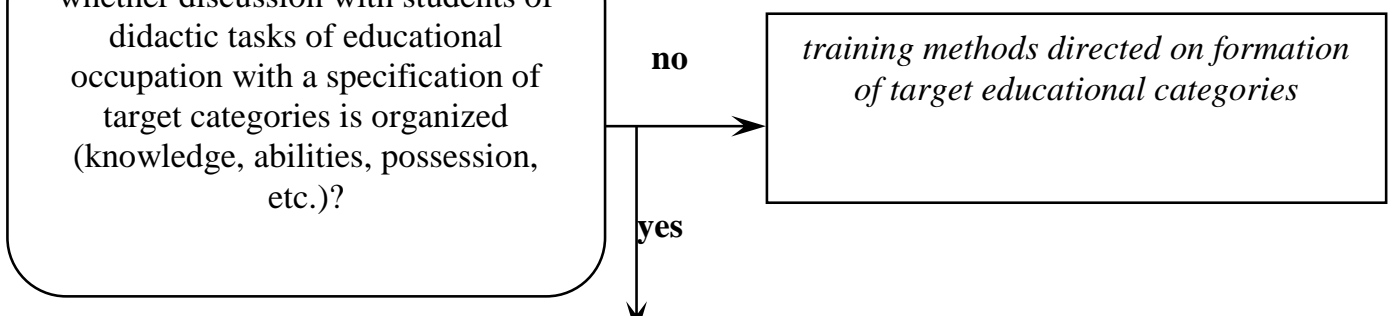

training methods aimedat formation of target educational categories development of abilities of students to formulate the purposes, tasks to allocate target categories and the structure of activity for achievement of the objectives

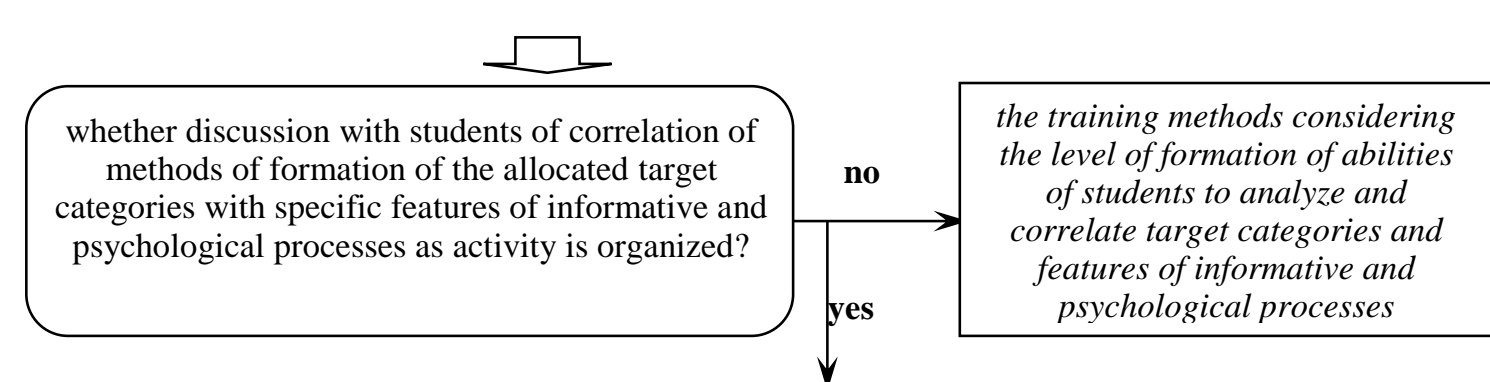

the personal focused training methods based on judgment by the teacher and students of correlation of target categories and specific features of informative and psychological processes 


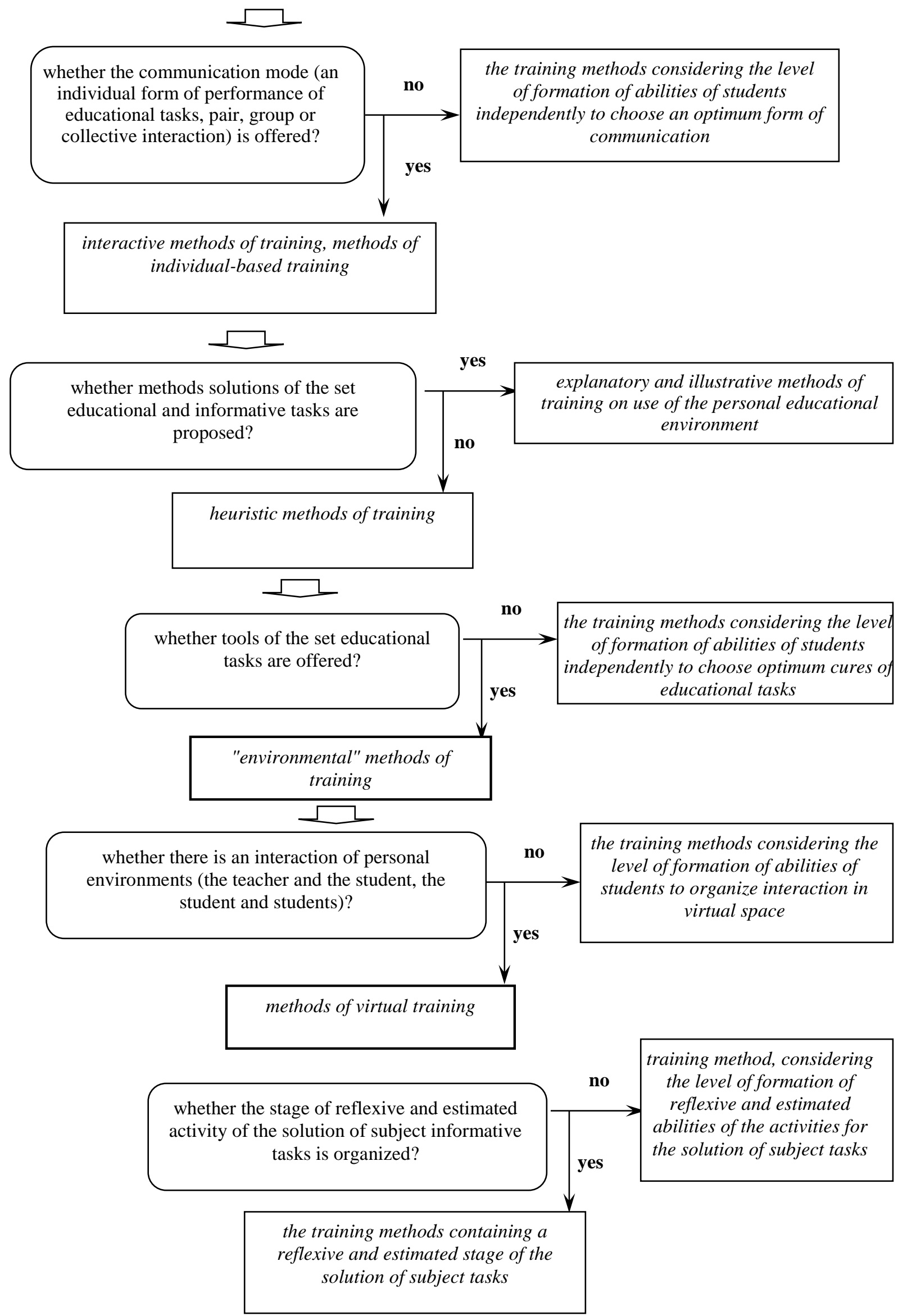

Fig.1. The scheme of design of methods of training of students with use of personal and virtual educational environments for formation of common cultural and professional competences. 
- specification and correction of the purposes and tasks of training, planning of level of achievement of educational results;

- selection of didactic units according to objectives of training and inclusion in their set of such unit as competence of design of the personal learning environment corresponding to components of allprofessional competence;

- the filling of the virtual environment by components which is carried out by selection of components according to tasks of training and data of psychology and pedagogical diagnostics in the course of joint activity with the teacher;

- choice of a way of management of environment, systems of the organization of information exchange, forms and control methods;

- a reflexive and estimated stage at which structural components of an individual educational trajectory locate the student, results of achievement of the educational purposes and performance of educational and informative tasks are traced and comprehended.

For convenience, we will present design stages of methods of training in the conditions of use of the virtual educational environment in the form of the scheme (fig. $1)$.

In the presented scheme, features of activity of the teacher at design of modern process of training for formation of common culture and professional competences, which need to be considered in the conditions of the personal educational environments filled by students, are recorded (see fig.1).

We will in addition indicate the need in introductions to ideologies of the offered technology of such concepts as "environmental" methods of training" and "methods of virtual training", which option of definition we will present as follows:

"Environmental" methods of training is a set of joint actions of the teacher and trainees on the organization of an exchange of educational information and management of her perception, understanding, storing and the correct application by means of the information and communication means which are (included trained) a part of the information educational environment.

Methods of virtual training are the individual-based methods of training constructed on the accounting of features of substantial filling of the personal educational environment of students, and also level of formation of the methods and their range used by students in this environment combined with the personal environment of the teacher.

\section{Conclusion}

In the modern information society, any subject of education has the self-adjustment personal educational environment.

Possibilities of information and communication space allow personal educational environment of students to be filled automatically with substantial content with which it is possible to carry out any kinds of educational (and professional) activity throughout the entire life. Therefore training methods in a modern educational paradigm cannot be projected without features and substantial filling of personal educational environment of students.

Thus we will note that if the process of design of modern educational activity will be carried out from positions of the classical didactics developing in the conditions of "scientific" [13] paradigms, at a certain stage of educational activity one inevitably will demand orientation to the personal educational circle of the student and the accounting of the specified features of VEE. However, implementation of the formulated requirement within a "scientific" paradigm cannot be carried out fully and correctly.

So, in a "modern" educational paradigm, methods of training of students have to be focused on use of personal educational environments, and activities for their design have to consider:

- substantial, methodical and technological features of the virtual educational environment;

- main design stages of educational technology;

- diagnostic data on the level of formation of components of common cultural and professional competences of a certain contingent of students.

The offered scheme is generalized for students of pedagogical specialties of training as it is focused on certain substantial components of common cultural and professional competence (in particular, the judgments and reflections of methods of own educational activity and methods of training of the teacher and an analysis stage of opportunities of using these methods assuming, for example, a stage in future professional activity for a certain contingent trained). However it contains possibility of specification and a specification for students of other orientation of training on the basis of theoretical results of the experts, investigating questions of filling the system of training methods in the conditions of using the virtual educational environment.

The following steps in the specified direction of research will be connected with creation of a technique of formation of abilities of students in using the personal educational environment for educational activity, a technique of formation of teacher'sabilities to use possibilities of personal educational environment of students for achieving educational purposes.

\section{References}

1. Structure of the ICT competence of teachers. UNESCO Recommendation. Available: http://iite.unesco.org/pics/publications/ru/files/3214 694.pdf

2. M.E. Bershadsky, V Guzeev,Didactic and psychological foundations of educational technology(Moscow: Teaching Search, 2003).

3. M.A. Chatti, Personalization in Technology Enhanced Learning: A Social Software Perspective. Dissertation. (Aahena University, 2010)

4. M. Harmelen, The Manchester Personal Learning Environment. http://www.jisc.ac.uk/events/ $\neg 2009$ /03/ngtip /mple.aspx 
5. D. Izmestiev, Personalized learning: A new ictenabled education approach UNESCO. Institute for Information Technologies in Education. http://iite.unesco.org/pics/publications/en/files/3214 716.pdf

6. V.Jadzgevičienè., J. Urbonienè, Business and Education 1(14) 3-9. (2013).

7. Z.A. Shaikh, Sh.A. Khoja, Role of Teacher in Personal Learning Environments Digital Education Review21 http://www.uh.cu/sites/default/files/ Role_of_Teacher_in_PLE.pdf, last accessed $2017 \overline{7} 07 / 10$.

8. V. Tomberg, Learning flow management and teacher control in online personal learning environment(Institute of Educational Sciences, Tallinn University. Tallinn, 2013)

9. M.E. Vayndorf-Sisoeva, Virtual Learning Environment: category, characteristics, diagrams, tables, a glossary(Moscow: MGOU, 2010)

10. I.N. Semenova, Methodology of teaching mathematics methods designing in the modern educational paradigm(Yelm, WA, USA: Science Book Publishing House, 2014).

11. B.E. Starichenko, Teach.ed. in Rus. 7 6-15 (2015).

12. D.A. Halim, N. Bilal Ali, M., Yahaya, N.: Personalized Learning Environment: New Trend in Online

Learning. http://eprints.utm.my/14943/1/Personalized_Learnin g_Environment.pdf, last accessed 2017/05/23

13. I.N.Semenova, Ped.ed. in Rus7, 67-76 (2016).

14. E.P. Antipova, Th.and pr. of phys. cult. 3, 48-50 (2010)

15. A.V. Slepukhin,Ped. ed. in Rus.782-90 (2016). 